\title{
The Outcome after Surgery of Patients with Congenital Cataract in the Outpatient Clinic of RSUD Dr. Soetomo Surabaya in January 2014 - January 2017
}

\author{
Lady Sherly Nuramalia ${ }^{1}$, Indri Wahyuni ${ }^{2}$, Prastiya Indra Gunawan ${ }^{3}$ \\ 1 Faculty of Medicine, Universitas Airlangga, Surabaya, Indonesia. \\ 2 Department of Ophthalmology, Faculty of Medicine, Universitas Airlangga - Dr. Soetomo General Hospital, Surabaya, \\ Indonesia. \\ ${ }^{3}$ Department of Pediatric, Faculty of Medicine, Universitas Airlangga - Dr. Soetomo General Hospital, Surabaya, Indonesia.
}

\section{A B S T R A C T}

Introduction: Congenital cataract is a leading cause of childhood blindness. Congenital cataract is characterized by an opacification of the lens that has existed from birth or shortly after birth. Congenital cataract can occur unilateral or bilateral. The cause of congenital cataract can be idiopathic, hereditary, chromosomal disorders, metabolic disorders, and infections. The use of intraocular lens implantation can provide better visual results. Whereas the results of cataract surgery with aphakia glasses correction showed poor results. This study aims to find out the outcome after surgery of congenital cataract patients in the outpatient clinic of RSUD DR. Soetomo Surabaya.

Methods: This research was a descriptive retrospective study. Samples were patients with congenital cataract diagnosis in the Outpatient Clinic of RSUD Dr. Soetomo Surabaya in January 2014 - January 2017.

Results: The results showed that there were 21 patients with congenital cataract. The most outcome after surgery of the patients with congenital cataract OS and OD were IOL positive, there were $14(70 \%)$ for OS and $14(77.77 \%)$ for OD.

Conclusion: Most patient outcomes after surgery was IOL positive.

*Correspondence: indry_budiarto@yahoo.com

JUXTA: Jurnal IImiah Mahasiswa Kedokteran Universitas Airlangga

p-ISSN: 1907-3623; e-ISSN: 2684-9453

DOI: $10.20473 / j u x t a . V 10122019.64-65$

Open access under Creative Commons Attribution-ShareAlike 4.0 International License (CC-BY-SA)

\section{ARTICLE INFO}

Article history:

Received 08 August 2019

Received in revised form 19 August 2019

Accepted 26 August 2019

\section{Keywords:}

Aphakia,

Congenital cataract, Intraocular lens (IOL),

Outcome 


\section{Introduction}

Congenital cataract is a leading cause of childhood blindness. ${ }^{1}$ Congenital cataract is characterized by an opacification of the lens that has existed from birth or shortly after birth. ${ }^{2}$ Congenital cataract can occur unilaterally or bilaterally. The cause of congenital cataract can be idiopathic, hereditary, chromosomal disorders, metabolic disorders, and infections. ${ }^{3}$ The use of intraocular lens implantation can provide better visual results. ${ }^{2}$ Whereas the results of cataract surgery with aphakia glasses correction showed poor results. ${ }^{4}$

Congenital cataract has a prevalence of $1-15 / 10,000$ live births with a greater presence in developing countries than in developed countries. ${ }^{3}$ The lower prevalence of blindness in developed countries may be the result of better cataract management. ${ }^{4}$ Every year, about 20,000 to 40,000 babies are born with congenital cataracts. ${ }^{5}$

This study aims to describe the outcome after surgery of patients with congenital cataract in the outpatient clinic of RSUD Dr. Soetomo Surabaya in January 2014 January 2017.

\section{Methods}

This research was a retrospective descriptive study using a medical record. Samples were medical reports of patients with congenital cataract diagnosis in the outpatient clinic of RSUD Dr. Soetomo Surabaya in January 2014 - January 2017. Sampling was carried out in total sampling.

Data collection in this study included patient outcomes after surgery. The collected data will be processed through Microsoft Excel and presented in tables.

This research has received ethical clearance from Health Research Ethics Commission of RSUD Dr. Soetomo Surabaya with number 553/Panke.KKE/IX/2017.

\section{Results}

The results showed that from the medical records in January 2014 - January 2017, there were 21 patients with congenital cataract.

Table 1. Patient Outcomes After Surgery (OS). $(\mathrm{n}=20)$

\begin{tabular}{lll} 
Outcome & $\mathbf{n}$ & Percentage \\
\hline IOL + & 14 & $70 \%$ \\
Aphakia & 5 & $25 \%$ \\
No Data & 1 & $5 \%$ \\
$\begin{array}{l}\text { Cloudy eyes } \\
\text { (No Action) }\end{array}$ & 0 & 0 \\
\hline
\end{tabular}

Table 2. Patient Outcomes After Surgery (OD).

$$
(\mathrm{n}=18)
$$

\begin{tabular}{lll} 
Outcome & $\mathbf{n}$ & Percentage \\
\hline IOL + & 14 & $77.77 \%$ \\
Aphakia & 2 & $11.11 \%$ \\
No Data & 1 & $5.55 \%$ \\
Cloudy eyes & 1 & $5.55 \%$ \\
(No Action) & &
\end{tabular}

Table 1 and Table 2 show that the most outcome after surgery of the patients with congenital cataract OS and OD were IOL positive, there were $14(70 \%)$ for OS and 14 $(77.77 \%)$ for OD.

\section{Discussion}

The most outcome after surgery of the patients with congenital cataract OS and OD were IOL positive, there were $14(70 \%)$ for OS and $14(77.77 \%)$ for OD. Based on these data, it showed that intraocular lens implantation was the most common thing done in patients with congenital cataracts.

In this study, the outcome was seen based on IOL use. If a congenital cataract patient after surgery uses IOL then it is stated as a positive IOL. However, if the patient after cataract surgery does not use IOL then it is declared a negative IOL or aphakia. So Aphakia is a situation where the eye is without a lens. ${ }^{6}$

Al Shamrani and Al Turkmani in their research showed that the ability of intraocular lens to provide a constant visual stimulus caused acceptance of intraocular lens implantation as an alternative form of optical correction. ${ }^{7}$

The use of intraocular lens implantation causes vision to be better. The results of this study were similar to the results of previous studies by Ledoux et al. They reported that out of 239 children aged 11 days to 17 years with unilateral or bilateral cataracts who performed primary IOL implantation, they found that about $75 \%$ of these children experienced better vision improvement. ${ }^{8}$ Congdon et al., also showed that the use of intraocular lens implantation can provide better visual results. ${ }^{9}$ Yorston et al., also showed that good results can be obtained using an intraocular lens, whereas the results of cataract surgery with aphakia glasses correction showed poor results. They also advocated the use of intraocular lenses as the treatment of choice for most children with cataracts in Africa. ${ }^{4}$

\section{Conclusion}

Most patient outcomes after surgery was IOL positive.

\section{Acknowledgement}

1. Department of Ophthalmology, Faculty of Medicine, Universitas Airlangga Dr. Soetomo General Hospital, Surabaya

2. Department of Pediatric, Faculty of Medicine, Universitas Airlangga Dr. Soetomo General Hospital, Surabaya

\section{CONFLICT OF INTEREST}

The author stated there is no conflict of interest in this study.

\section{REFERENCES}

1. Sheeladevi S, Lawrenson JG, Fielder A, et al. Delay in presentation to hospital for childhood cataract surgery in India. Eye. 2018; 32: 1811-8.

2. Shiels $A$ and Hejtmancik JF. Mutations and mechanisms in congenital and age-related cataracts. Experimental eye research. 2017; 156: 95-102.

3. Messina-Baas $O$ and Cuevas-Covarrubias SA Inherited Congenital Cataract: A Guide to Suspect the Genetic Etiology in the Cataract Genesis. Molecular syndromology. 2017; 8: 58-78. 
4. Yorston D, Wood M and Foster A. Results of cataract surgery in young children in east Africa. The British journal of ophthalmology. 2001; 85: 267-71.

5. Tomkins O, Ben-Zion I, Moore DB and Helveston EE. Outcomes of pediatric cataract surgery at a tertiary care center in rural southern Ethiopia. Archives of ophthalmology (Chicago, III : 1960). 2011; 129: 12937.

6. Haszcz D, Nowomiejska K, Oleszczuk A, et al. Visual outcomes of posterior chamber intraocular lens intrascleral fixation in the setting of postoperative and posttraumatic aphakia. BMC Ophthalmology. 2016; 16: 50.

7. Al Shamrani $\mathrm{M}$ and Al Turkmani S. Update of intraocular lens implantation in children. Saudi $J$ Ophthalmol. 2012; 26: 271-5.

8. Ledoux DM, Trivedi RH, Wilson ME, Jr. and Payne JF. Pediatric cataract extraction with intraocular lens implantation: visual acuity outcome when measured at age four years and older. Journal of AAPOS : the official publication of the American Association for Pediatric Ophthalmology and Strabismus. 2007; 11: 218-24.

9. Congdon NG, Ruiz S, Suzuki M and Herrera V. Determinants of pediatric cataract program outcomes and follow-up in a large series in Mexico. Journal of cataract and refractive surgery. 2007; 33: 1775-80. 